\title{
Weaknesses and Opportunities in Implementing Public Service Policy in the Government of
} Palembang, Indonesia

\author{
Hardiyansyah \\ University of Bina Darma, Palembang, Indonesia \\ hardiyansyah@binadarma.ac.id
}

\begin{abstract}
The enactment of Indonesian law No. 25 of 2009 on Public Service is a milestone and a hope to the realization of public services quality. The substance of this law has led to the implementation of public services quality expected by all parties (stakeholders). This article is about to discuss the implementation of public service policy in Palembang. By using qualitative descriptive method, the conclusion showed that there are some weaknesses in the implementation of public service policy: (1) the information submitted is inaccurate, incomplete, inchoate; (2) Staffing / apparatus are still not in accordance with the disciplines and expertises; (3) Unclear job descriptions and procedures, by who does the job and to whom should be the report submitted; (4) The use of facilities, infrastructure is not optimal use; (5) The behavior of officers and management commitments are still low; (6) The incentives expected are still in material / value for money; (7) Awards and supports given to the implementor are still very low; (8) The organizational structure is "gemuk/tambun" (increasing); (9) Duplication of duties and functions among related agencies. While the opportunities that can be exploited are: (A) The use of information technology using online services; (B) Higher educational qualifications of apparatus; (C) Some facilities and infrastructures have been adequate; (D) With the slogan "Miskin struktur dan Kaya fungsi" (lean and mean) is expected to realize the organizational structure more effective, efficient, and easier for public services.
\end{abstract}

Keywords: Policy Implementation, Public Service, Palembang

\section{Introduction}

Before the reformation era, the implementation of state and government characterized by the practice of maladministration including corruption, collusion, and nepotism that is why absolutely necessary to reform the bureaucratic organization to realize the implementation of good state and government, effective and efficient, honest and clean, transparent and free from corruption, collusion, and nepotism. Good state administration and governance can only be achieved by improving the quality of state and government apparatus and law enforcement on principles of public governance (Explanation of Law No. 37 of 2008 on the Ombudsman). Nurman (2016) says that the most important purpose of public service is to give satisfaction to the public with the applicable standard of service quality, through optimal service strategy based on the performance of human resources. Furthermore, the performance of the government staff who provide public services are required to be upgraded by doing some workshops and training on public service quality. Various policies, regulations, rules, and other means have been tried and provided by the government/local government to the realization of public services quality. But in fact, in reality shows that the services are still much less from what to be expected by all people (stakeholders). Finally, the government together with the legislature has enacted Law No. 25 of 2009 on Public Service. Article 3 states that the aims of the Law on Public Service are: (a) establishing boundaries and clear relationship among rights, responsibilities, obligations, and authorities of all parties related to the provision of public services; (B) establishing a eligible system of public service in accordance with the general principles of good corporate governance; (C) the fulfillment of public services in accordance with the legislation; and (d) Establishing protection and legal certainty for people in public service.

So far, the position of populace in public service activities is at a forced circumstance and there is no choice but undergo with variety will of apparatus who serves them. Under these conditions, the policy implementation of Law No. 25 of 2009 on Public Service at one side provides enlightenment and hope for better conditions, but on the other hand, in fact that there is now still a lot of frauds, especially in the city of Palembang as informed by Komisi Pemberantasan Korupsi (KPK) (Indonesia's Corruption Eradication Commission). KPK exposes some frauds in public services in Palembang, from public service in land agency, 
vehicle tax services, civil records, immigration offices, notaries and others. Governor of South Sumatra (Alex Noerdin) promises, if there is no better change to the next three months, the office of the public service will be taken into legal action. This was revealed in a seminar on eradication corruption, with the theme of eradication corruption through improving the quality of public services, which was held at Hotel Aryaduta Palembang. Governor of South Sumatra (Pratama, 2010) says that "Despite of many indications of poor public services and rampant of corruption cases, but we still have to be optimistic, because many local governments have been able to improve public services, because the spirit of otonomous local government attempt to provide ample opportunities area with many innovations and improvements on public services, such as one-stop services to cut bureaucracy and corruption which has been implemented by South Sumatra government at office PTSP BPMD in South Sumatra". Based on the introduction above, this article will discuss comprehensively on "Implementation of Public Service Policy: the Analysis of Weakness and Opportunities in Palembang."

\section{Literature Review}

The concept of Policy Implementation: Implementation of the policy, in general, is an action of policy process soon after the laws are set by regulatory authorities, and subsequently carried out by the government, individually or by groups of people to achieve goals. The actions undertaken must be capable of linking between goals defined with the realization, or the results that will be or have been performed, so there will be synchronization. Grindle (1980:6) corellated between the goals of public policies to the realization of outcomes from the activities done by government, he states that: In general, the task of implementation is to establish a link that allows the goals of public policies to be realized as outcomes of governmental activity. In involves, therefore, the creation of a "policy delivery system", in which specific means are designed and pursued in the expectation of arriving at particular ends.

The activities in an organization are undertaken by government officials who have the authority based on appropriate mechanisms and procedures, and utilizing facilities and infrastructure provided as well as done together to achieve goals. Regarding to the meaning of implementation, Lester and Stewart (2000) argues that Implementation means undertaking the laws in which various actors, organizations, procedures, and techniques work together to implement policies in the pursuit of policy goals or programs. Implementation on the other hand is a complex phenomenon which may be understood as a process, an output as well as an impact (outcomes). The definitions above indicates that the implementation of the policy is to realize the laws in the form of work programs more operational by actor/implementor in well designed organization, carried out with the working procedures and techniques, and done together to achieve the goals of the policy. In fact, in reality shows that policy implementation is complex, because the implementation is a system that can not be separated from the sub-systems existed (input - process - output) to the outcome or impact.

The impact of the implementation of the policy is the main target, therefore consensus or agreements from subordinate officials (implementors) are required to participate. Furthermore, this consensus shows that motivation and responsibility from implementor in estalishing the organization as a place to undertake the public trust and prosperity to be realized. Gross and Berstein in Winarno (2007) suggests the factors that affect the consensus in achieving the goals, namely: First, staff participation leads to high motivation and it is necessary to successful implementation; second, participation causes great commitment, and high commitment affect to changes; third, participation creates greater clarity about a renewal, and clarity is needed for implementation; and fourth, participation facilitate the successful implementation; the subordinates will tend to oppose reformation, if initiatives on the implementation of the policy comes individualy from their superior officials.

Other experts' point of views, that absolute implementation policy consists of three (3) main elements that are related to each other as a system. According to Abdullah (1988), the three main elements include: "1) implementing elements (implementor); 2) the program will be implemented; 3) the target groups". At the government level, the parties especially obligated to implement public policies are administrative units or units of the bureaucracy (Ripley \& Franklin, 1986). The government bureaucracy undertaken as the responsible party for the implementation of policies in the hierarchical position is authorized official 
personnel within the organizational structure. Authorized personnel regarding to Winarno (2007) can be measured from: First, the officials is taking responsible in recruitment and selection, assignment and correlation, promotion, and dismission. Secondly, officials shall control the budget at existing units, and have the authority to respond to policy achievement whether satisfactory or unsatisfactory, and have the authorityr to influence the behavior of subordinates. The responsibilities undertaken by government is responsbility in policy implementation programs that have been created and agreed in advance through public policy decisions. Tachjan (2008) states that: "The essence of the policy implementation is implementing the programs". Grindle (1980) supports that: "Implementation is that set of activities directed toward putting a program into effect". Various operational programs are to be understood by the implementor / executor on programs related to various aspects of the contents, purposes/goals of the programs, allocating budget and the accuracy of the designation, methods and procedures work properly, and the clarity standards for guidance in the policy implementation.

Policy Implementation Models: Some experts have different views on the success of policy implementation when applied in reality. it means that there are some experts state that the implementation of the policy can be successful if it is mutually supported by reinforcement factors as an interconnected system, and on the other hand, some experts suggest as variables. Various views and sugestions related are logical because it depends on the context in which policy experts. In reviewing various factors or variables affecting the implementation of the policy, the writer shall present several models of policy implementation as following:

First, Edwards III Model: Edwards III (1980) argues that in reviewing policy implementation, first need to be asked the following questions: "What are the preconditions for successful policy implementation? What are the primary obstacles to successful policy implementation?" It means what a prerequisite for the successful policy implementation? What are the main obstacles to successful policy implementation? Edwards tries to answer two important questions by outlining four crucial factors or variables in policy implementation. These factors are: communication, resources, dispositions or attitudes, and bureaucratic structure (Edwards III, 1980). These factors influence the policy implementation and work simultaneously, and interact one another to help and hinder the policy implementation. It can be shown on Fig.1 of how the relationship between the factors influencing each other, either directly or indirectly to the policy implementation, it can be described as follows:

\section{Figure 1: Policy Implementation (Edwards III, 1980)}

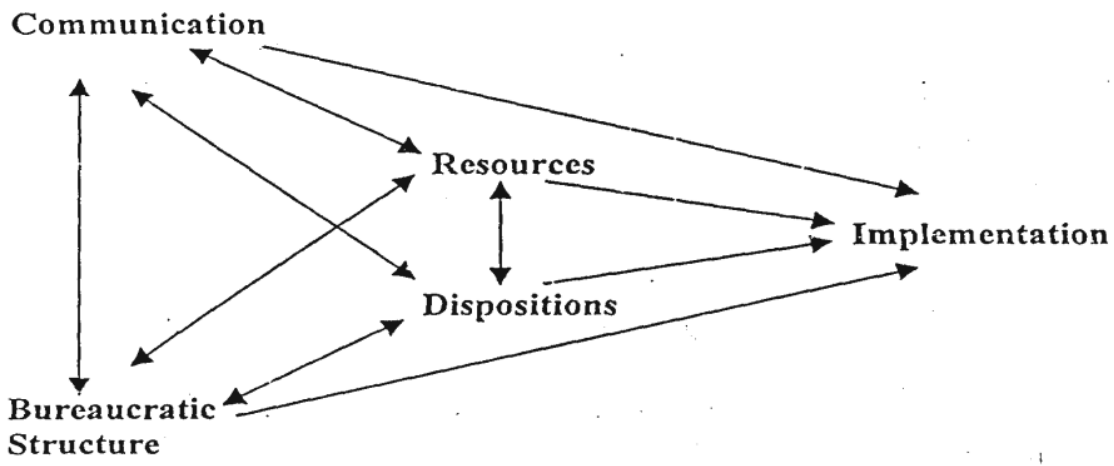

From Fig. 1, it shows that factors of communication, resources, attitudal implementor, and the bureaucratic structure may directly affect the implementation of policy. Furthermore, these factors indirectly influence the implementation of policy through the impact of each factor. In other words, each factors interferencely affecting, then simultaneouly influence the policy implementation. Second, Van Meter and Van Horn Model: Meter and Horn (1975) state that the performance of policy implementation is basically an assessment of achievement level of specific standards and targets set out in a policy. The model they developed known as A Model of the Policy Implementation Process. This model explains that the policy performance is influenced by several interrelated variables. Models offered include six variables that make up the association (linkage) 
between policy and performance. This model not only defines the relationships between independent variables and the dependent variables, but also describes the relationship between the independent variables. These variables as described by Tachjan (2008), include: standards and goals of policy, resources, implementing organizational characteristics, communication between associated organizations with implementation activity, the attitude of the implementor, social, economic and political.

Determining indicators to measure the success of the policy implementation is crucial stages faced by the implementor in the field. Therefore, Meter and Horn suggest that before a policy is implemented, it needs to be predetermined written standards and goals of program, so that the implementor perform their activities refer to existing standards, and the work is done in line with the goals. Winarno (2007) more specifically interprets Meter and Horn's thoughts; particularly in organizational communication needs to be updated are the recruitment and selection, assignment and relocation, promotion and dismission. It means that the nature of organizational communications is firm, but walks in the corridor or following the existing rules and does not put aside the ambience of flexible communications, humorous and comfortable atmosphere are needed. Communication organization is often too tense, even heats up between officials and implementors caused by miss-interpretation between implementor of policies in implementation activity, such as lack of funds, among implementors do not work on target, and there may not be synchronization between the result of performance conditions in the field.

The policy Implementation cannot be separated with the characteristics of the implementation agencies which affecting the policy achievement. The characteristics of these agencies identified by the Meter and Horn as bureaucratic structure. The bureaucratic structure is generally characterized by rigidity in the workflow, too strict norms and patterns of relationships, applicable routines in the organization or institution that enables dynamic atmosphere is not created. The desirable tendency is less formal and less restricted circumstance and not by too rigid boundaries. Next variables are the economic conditions, social and political. To assess the performance of policy implementation needs to be considered is the extent of the external environment which contributes to the success of public policies. Inconducive social environment, economic, and political could be the culprit of the failure to the policy implementation performance.

Third, Grindle Model: Grindle Model (1980) is known as top-down approach. This approach is well known with: Implementation is A Political and Administrative Process. According to Grindle, variables affecting public policy implementation consist of two things: first, the question whether the implementation of the policy determined (designed) is in accordance with the action policy. Second, whether or not the policy goals are achieved. The criteria are viewed from two factors: 1) the impact or effect on the society as individuals or groups; 2) the level of changes and the acceptance level by public wheter individually or in group. Therefore Grindle (1980) comments on the implementation of the policy as follows: The implementation of the actual policy are not simply concerned with the mechanism of defining of political decisions into routine procedures through the channels of bureaucracy, but more than that, it is related to the conflicta, decisions, and who is getting what from a policy.

The framework suggested by Grindle (1980) on the implementation of policies, particularly in developing countries, is determined by the degree of implementability of the policy, namely Content of Policy (policy content) and Context of Implementation (context implementation). A description of the variables influencing each other in the policy implementation is described in the following illustration. 
Figure 2: Implementation as a political and administrative process (Grindle, 1980)

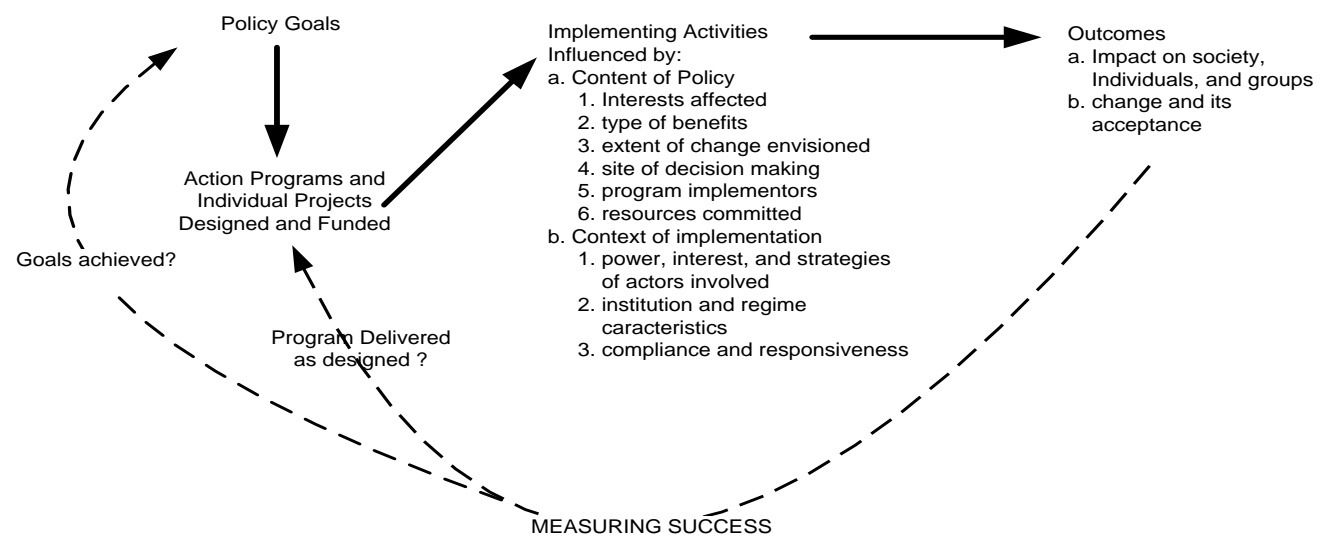

Some models of the policy implementation described above basically have the advantage in according to the view of experts' suggestions to the model and the context in which the policy is implemented. There is no single variable considered perfect right or appropriate well in the policy implementation activity. The success of the policy implementation is determined by many factors, both related to the implemented policy, implementor of policy, and the environment in which this policy is implemented (target group). In this article, the writer shall propose and elaborate the Implementation of Law No. 25 of 2009 on Public Service in Palembang using Edwards III Model Approach. The main reason of adopting the Edwards III Model is that the four dimensions of the model can comprehensively explain the policy implementation.

The essence of Public Service: According to Article 1 act (1) of Law No. 25 In 2009, public service is an activity or series of activities to meet the needs of service in accordance with the laws for every citizen and people for getting goods, services, and / or administrative services provided by public service providers. The essence of public services according to Ibrahim (2008) are: (1) improving the quality and quantity/productivity; (2) performing the duties and functions of the agency (institution) of government/governance in public services; (3) encouraging all efforts to effectiveness and efficiency of the implementation systems and procedures, so that public services can be organized more efficiently and effectively; and (3) encouraging the growth of creativity, participation and the role of public in developing and improving social welfare.

\section{Methodology}

To define comprehensively and naturally on the implementation of public service policy in Palembang, the design of the research is a qualitative method with descriptive approach. To analysis the data descriptive method is used, and case study is used to find the facts in interpreting and describing the essence of some phenomena occured and then to explore and clarify the phenomena or social reality. The data used in this research are including facts and information regarding the implementation of Law No. 25 of 2009 which were obtained through interviews with informants and observation, and the information from informants related to the object of research problems and secondary data obtained from a variety of documents, archives, journals, scientific papers, statistical data, maps, and other organizational structures. Informants in this study are the people who are requested the information in accordance with the social status or position. The informant in this research field of public service officials (integrated service office), members of the local legislative commission III, and people who use services that are incident. The main instrument in this study is the writer himself as the researcher and supplemented additional instruments such as recorders, cameras, mobile phones, stationery such as pencils, pens, papers, books, markers, and many others. 


\section{Results and Discussion}

Weaknesses and Opportunities: As described above, that the problems in a policy often have appeared on implementation, due to related parties (stakeholders) with that policy are very heterogeneous and complex dealing with a variety of community characteristics. Suppose that the number of people in an area is two million people, and then it means that there are two million people characteristics that must be accommodated in the implementation of existing policies. Various characteristics of the community, of course there will be an opportunity or a success factor in the policy implementation and along with that also there will be a factor of weakness. More or less, opportunities of success and weaknesses of implementation of policy are also greatly influenced by what, who, where, when, why and how this policy shall be implemented.

Regarding to relationship and connection with the policy implementation on public services using Edwards III Model approach in terms of the opportunities and weaknesses in Palembang, based on interviews, observation, and empirical data as well as the results of previous research, can be concluded a series of analyzes as follows: According to Edwards III, there are four factors affecting the policy implementation. These factors include: communication, resources, attitudes of implementors, and bureaucratic structures. Each factors influence the policy implementation through the impact of each factor. In other words, each of these factors interferently affecting, then simultaneouly influence the policy implementation. Furthermore, each of these factors or variables influences each other, either directly or indirectly to the implementation of the policy, described as follows.

Communication Factor: Clarity of standard and purpose of the policy is necessary to be designed appropriately with the implementors. The consistency of standards and goals need to be communicated so that the implementors know the exact standard and purpose of the policy. Communication within the organization is a very complex and complicated process. A person can hold only for specific purposes, or redistribute it. In addition, different sources of information will also provide different interpretation. In order to have effective implementation, implemetors who are responsible for implementing a decision have to find out wheter or not they are capable of doing the duty. Actual implementation of the policy must be accepted by all personnel and must be clear and accurate about the aims and goals of policy. If the actors of policy makers have seen ambiguity in policy specifications, actually they do not understand what it actually means to be redirected. The policy implementors are confused for what they are supposed to do and if they have to do it so there will be no optimal outcomes achived. Insufficient communication to the implementors seriously affects the policy implementation.

Based on the research results from Hardiyansyah (2011), communication significantly affects the service quality on Izin Mendirikan Bangunan (IMB) (building permit) at the Department of City Planning, Palembang. The amount of influence on the quality of IMB service communication is determined by the dimensions of communicators, message, media, communicants, and effects. On the communications dimension, there are opportunities that can be exploited, namely the use of communication technology using online service. The internet facility in Palembang strongly supports these services, even some areas provide free hot-spot and wifi facilities for users. It means that if the communication technology is utilized properly and optimally, public services can be accesed easier, cheaper and faster. However, the policy implementation on Law No. $25 / 2009$ still has many weaknesses, such as the information submitted is inaccurate, incomplete, inchoate and sometimes does not publish notice of public services and it is contrary to Article 15 (b) of Law 25/2009. There is still a habit of hiding information such as unclear and confusing rate/service charge and convoluted procedures, such as service for IMB, permit of business place, and the trade license and others.

Resources Factor: The resource components include the number of staff, the expertise of the executive, relevant and sufficient information to implement compliance policies and related resources in the implementation of the program, the authority which ensures the program can be redirected as expected, as well as supporting facilities which can be used to conduct program activity such as funding and infrastructures. The results of the research by Wawointana, et al (2016) state that public service in security and public order is not optimal due to the lack of Local Government role in the values of "Mapalus" (mutual cooperation) in policy formulation and implementation, and budget funding factor less transparent, and 
management of human resources is incompetence, and attitude of local governments less responsive. Inadequate human resources (numbers and capabilities) resulting in the implementation of the program is not perfectly implemented because they can not supervise properly. When the number of staff in implementing policy is limited, then the thing to do is to increase the skill/ability of the executive in implementing the program. In addition, we need good human resources management in order to improve the program.

Based on resource factors, there are some opportunities that can be exploited for the successful implementation of the policy of Law No. 25/2009, including the personnel education backgroun who have bachelor's and master (72.54\%) as well as supporting facilities are quite representative. However, some things can also be a weakness in the implementation of public service policy, such as staffing / personnel are still not in accordance with the disciplines and expertise, it is contrary to Article 14 (c) of Law 25/2009. Because the laws or regulations of the public service, both articles and acts are too many explanations, therefore, to explain all things related to the service policies takes a long time, so that the information is incomplete, unclear and inaccurate. The other weaknesses are related to the authority. Although the authority is in conformity with the job description and duty of each function, but still often be found vagueness of who does and to whom these matters should be reported as well as the use of facilities, equipment and infrastructure are not yet optimal.

Disposition Factor: There are two forms implementor attitudes towards the policy, namely: implementing awareness, and understanding in response to the program so that it can be accepted or rejected. The implementors may understand the purpose and goals of the program, but often fail in implementing certain programs because they refuse the goals in the program so they surreptitiously divert and avoid implementing the program. In addition, the support of the executive officers are needed to achieve the goals of the program. Support from the leadership greatly affects the implementation of the program to achieve the goals effectively and efficiently. The realization of this leadership support is contributing to priority policy, promoting implementor with those who support the program, observing local conditions, religion, ethnics, genders and other demographic characteristics. Besides that, the provision of sufficient funds is necessary to provide incentives for implementor of the program, in order they can totally support and work well in implementing the policies/ programs. On this factor, only a few weaknesses found, for example, the behavior of officers who are willing to be obedient for value money paid and the apparatus response in the service is still low, and the commitment of the leadership to improve the quality of service is still low. The incentives expected are still in material/value money, so the size of the incentives based on the nominal money will be received. In fact, incentives not only in form of money, it may be in the form of recognition of achievements, awards and supports. Awards and supports given to the implementor are still in minimum level, almost no appreciation and support regards to the achievements made by the implementor.

Bureaucratic Structure Factor: The structure of the bureaucracy in the policy implementation has an important role beside communication factor, resources, and behavior of the implementors. One of the most fundamental aspects in the structure of the bureaucracy is the Standard Operating Procedure (SOP). SOP gives directions to the executor or implementor in the use of time, implementation activity, including the actions of officials. SOP also gives opportunity to the implementor in an organization when mutations or transfering employee to another position. SOP gives a clear guidence for employees to implement new activities to whom and what the contents are demanded in his work. Edward III sugests variables or crucial factors that influence the implementation of policy and there are some important things to be noticed: first, variables or crucial factors to be standard to measure the product of a policy made by the government, whether national, regional or local level in an effort to increase the prosperity of society according their needs and their expectations. To meet the needs and expectations of the society is the responsibility of the government in the form of intervention in various policies. Second, in implementing a policy, ideally the government has prepared variety of possibilities/alternative actions in case something unexpected happens; The third, in the policy implementation, the characteristics of the target group needs to be taken into account, so that between the implementor and the target group are synergizing and finally the implementation of policies achieve the expected goals. 
From bureaucratic structure factor point of view, there are some opportunities that can be exploited for the success of policy implementation of Law No. 25/2009. These opportunities include: The slogan "lean and mean" is expected to realize a lean organizational structure and would be easier to do service. While the weakness that still will be a problem is personnel/staff that entered the election campaign team, then they need to be accommodated in structural positions. It is necessary to make bureaucratic structures to be lean but not to be "gemuk/tambun" (increasing). because it makes service provided becomes slow, difficult, complicated, and even discriminatory. Duties and functions are clear, but still frequently much duplication among local government agencies related, so that service is not effective and the capacity of the team is also less optimal.

\section{Conclusion and Recommendations}

Based on the discussion and analysis above, it can be concluded that the implementation of Public Service policy in the Palembang still face many weaknesses, among others: (1) Often, the information submitted is inaccurate, incomplete, inchoate and do not publish notice of service to the public, habit of hiding information such as rates / service charges are unclear and confusing. The convoluted procedure; (2) Staffing/apparatus are still not in accordance with the disciplines and expertise, contrary to Article 14 (c) of Law 25/2009; (3) Although the authority is in conformity with the basic tasks and functions of each, but they often found vagueness of who does what and to whom should be reported; (4) The use of facilities, infrastructure is not optimal; (5) conducting an obedient apparatus provided depend on compensation, and apparatus response in the service is still low, and the commitment of the leadership in improving service quality is still low; (6) The incentives expected are material/value money, so large of the incentives depends on nominal money received. Actually incentives are not only money, but also may be recognition of achievements, awards and support; (7) Awards and the support given to the implementor is still very low (8) Since the number of personnel/staff who entered the election campaign team, then they need to be accommodated in structural positions. Bureaucratic structures do not become lean, but getting "gemuk/tambun" (increasing). As the result of service given is slow, difficult, complicated, and even discriminatory; and (9) The primary task and function well indeed clear, but still many duplication of duties and functions among related institutions or agencies, so that service work is not effective and the carrying capacity of the team is also less optimal. Some opportunities that can be exploited for successful implementation of public service policy in Palembang are: (1) Utilizing information technology with online services; (2) Education level of apparatus; (3) Adequate facilities and infrastructure; (4) With the slogan "lean and mean" is expected to realize a lean organizational structure and to be easier for provising qualified public service. Recommendations can be given the appropriate conclusions obtained by minimizing the weaknesses and exploit the opportunities that arise optimal.

\section{References}

Abdullah. (1988). Application Development and Implementation Studies (Action Research and Case Studies). Jakarta: LAN.

Edwards III, G. C. (1980). Implementing Public Policy. Washington, D.C: Congressional Quarterly Press.

Grindle, M. S. (1980). Politics and Policy Implementation in the Third World. New Jersey: Princeton University Press.

Hardiyansyah. (2011). Quality of Public Services. Concept, Dimension, Indicators, and Implementation. Yogyakarta: Gava Media.

Ibrahim, A. (2008). Theories and concepts of public service and its implementation. Bandung: CV. Mandar Maju.

Law of the Republic of Indonesia Number 25 of 2009 on Public Services

Law of the Republic of Indonesia Number 37 of 2008 on the Ombudsman

Lester, J. P. \& Stewart, J. Jr. (2000). Public Policy; an Evolutionary Approach. Belmont, CA.: Wadsworth.

Meter, D. V. \& Horn, C. V. (1975). The Policy Implementation Process: A Conceptual Framework, in Adimistration and Society 6, 1975. London: Sage.

Nurman. (2016). Strategic to Improve Public Service System in Indonesia Government. The Social Sciences, 11: 1269-1276. DOI: 10.3923/sscience.2016.1269.1276. 
Pratama, A. (2010). https://informasipagi.wordpress.com/2010/09/30/kpk-beberkan-kecuranganpelayanan-publik-di-palembang/ (accessed on August 24, 2015)

Ripley, R. B. \& Franklin, G. A. (1986). Policy Implementation and Bureaucracy. Chicago: The Dorcey Press.

Tachjan. (2008). Implementation of Public Policies. Bandung: AIPI Bandung - Puslit KP2W Lemlit Unpad.

Wawointana, T., Haedar, A., Suradi, T. \& Ferdinand, K. (2016). Role of Local Institutions Mapalus as a Basis of Public Service in the Field of Security and Public Order in Minahasa, Indonesia. The Social Sciences, 11: 3370-3374. DOI: 10.3923/sscience.2016.3370.3374

Winarno, B. (2007). Theory and Public Policy Process. Yogyakarta: Media Pressindo. 